\title{
RESEARCH
}

\section{NON INVASIVE MECHANICAL VENTILATION IN THE ELDERLY UNDER SPECIAL CONDITIONS}

Turkish Journal of Geriatrics

DOI: 10.31086/tigeri.2021.206

2021; 24(2): 113-121

- Ebru ORTAÇ ERSOY 1

CORRESPONDANCE

\section{${ }^{1}$ Ebru ORTAÇ ERSOY}

Hacettepe University Faculty Of Medicine, Department of Internal Medicine, Division of Intensive Care, Ankara, Turkey

Phone: +905058189116 e-mail: ebru.ortac@hacettepe.edu.tr

Received: Mar 19, 2021

Accepted: May 20, 2021

${ }^{1}$ Hacettepe University Faculty Of Medicine, Department of Internal Medicine, Division of Intensive Care, Ankara, Turkey

\section{Abstract}

The proportion of elderly persons among hospitalized patients, including ICU admissions, is growing rapidly. Because of the severity of their comorbidities, the elderly patients have poorer prognoses than their younger counterparts. Acute respiratory failure (ARF) is the common cause in both ICU and hospital admission, The first method to treat ARF in the elderly is oxygen therapy via a nasal canula, face mask, or high-flow nasal cannula (HFNC) to buy time to reverse the cause of respiratory failure. Non invasive ventilation (NIV) should be the first choice in elderly as in younger when needed to mechanical ventilation for avoiding the need for invasive mechanical ventilation, as well as to prevent its complications. Although NIV could be considered a proper therapeutic tool in elderly population with ARF, some peculiar issues should be considered such as environment, selection of patients, palliative care and "end-of-life" decisions The use of NIV is an important and effective treatment both in de novo, acute on chronic, post-extubation respiratory failure and also, domiciliary and palliative setting in elderly. Age need not be a barrier to NIV treatment. In this review, usage of NIV in elderly in specific conditions will be discussed.

Key words: Noninvasive Ventilation; Aged; Respiratory Insufficiency; Critical Care 


\section{INTRODUCTION}

People are living longer all around the world. Ten percent of the world's population's age moreover 60 years, and this age group is expected to double by 2050 (1). The population is ageing so it may be concluded that elderly patients represent a distinct and important subgroup of patients. The proportion of elderly persons among hospitalized patients, including ICU admissions, is growing rapidly. Adults older than 65 years of age account for nearly half of ICU admissions $(2,3)$ although the proportion of older patients varies considerably across ICUs and countries.

Elderly patients have poorer prognoses than younger patients, and their mortality or morbidity depends on the severity of the underlying disease (3). Although acute respiratory failure(ARF) is the common cause in both ICU and hospital admission, chronic respiratory failure is also effecting elderly. The first method of treating ARF in the elderly is oxygen theraphy via a nasal canula, face mask or high flow nasal canulla (HFNC) $(4,5)$ to buy time to reverse the cause of respiratory failure. Mechanical ventilation is also an important therapy for this patient population. As for younger populations, non-invasive ventilation (NIV) should be the first technique used on the elderly to avoid the need for invasive mechanical ventilation unless absolutely necessary (6).

Nowadays respiratory failure due to Covid 19 pneumonia has seen frequently in elderly. Cases in those aged 70 to 79 years had an $8.0 \%$ and cases in those aged 80 years and older had a $14.8 \%$ mortality rates (7). It is important for these patients to support ventilation with NIV. In Covid 19 cases use of helmet mask as interface adviced because of staf protection.

For those with ARF, including patients of an advanced age, NIV successfully prevents unnecessary intubation and a prolonged hospital stay, and reduces the hospital mortality rate, particularly for patients with hypercapnic acidosis. However, if patients with ARF exhibit a lack of airway protection, inadequate cooperation, and a cough reflex, then NIV should be switched off, and intubation for IMV should be considered (6). Many elderly patients, especially chronic patients, are subsequently discharged on NIV home mechanical ventilation (NIHMV) to reduce subsequent hospital admissions, maintain their quality of life, and relieve symptoms of chronic hypoventilation (8).

The elderly is particularly fragile, so the use of NIV on this population invokes specific considerations. It should be considered a good alternative to IMV for treating acute or chronic respiratory failure under specific conditions, even for those with a do-not-intubate order $(4,8)$. Elderly patients with acute hypoxic and /or hypercapnic respiratory failure can be successfully treated with NIV. However, frailty is associated with higher NIV application problems as well as failure and mortality in the elderly, especially in ICU patients, so more attention should be paid to these patients. Frailty scores can be used to identify frail patients, predict NIV success, and improve ICU outcomes.

The success of the NIV technique is variable and depends on various factors, such as the experience of the staff applying it, adherence to the scheduled treatment, air leaks, adequate apparatus (mask, circuit), patient-ventilator synchrony and environment, the pathophysiological pattern, and the timing and severity of ARF and adequate sedation of patient (9) even the patient is fragile or not.

NIV is the first-choice ventilatory technique to treat certain diseases which are highly prevalent among the elderly; e.g., COPD, cardiogenic pulmonary edema, immunosuppression of various origin, neuromuscular disease, obesity hypoventilation syndrome, and chest wall deformity (10). The advantage of NIV is that it offers the same physiological effects of IMV delivered via ETI such as unloading respiratory muscles, improving gas exchange, and augmenting alveolar ventilation. NIV reduces the risks correlated with the use of endotracheal tubes, 
such as ventilator-associated pneumonia, for which the incidence rate is especially high in the elderly (8-11). Since most patients receiving NIV are managed with minimal or no sedation because of mask intolerance due to pain, discomfort, or claustrophobia (9), early weaning off from the ventilator is facilitated and sedative drug-related complications are avoided. The early use of NIV in addition to oxygen and medical therapy for the management of ARF reduces the rate of intubation, the length of hospital stays, and the hospital mortality rate, especially in acidotic hypercapnic patients, including those who are elderly (8).

Although NIV can be considered a proper therapeutic tool for the elderly population with ARF, certain issues should be considered pertaining to the environment, selection of patients, palliative care, and "end-of-life" decisions. NIV can be used in the elderly for different purposes: 1) life support without limits, whereby the primary goal is to assist ventilation and reduce the risk of intubation and mortality, eventually restoring health; 2) life support with limits, whereby the goal is to restore health without using endotracheal intubation and the response to failure is mainly to palliate symptoms without using $\mathrm{NIV}$; and 3) comfort measures for palliation to maximize comfort and minimize adverse effects.

The use of NIV is an important and effective treatment for de novo, acute-on-chronic, and post-extubation respiratory failure in both domiciliary and palliative settings for the elderly.

Age need not be a barrier in NIV treatment. In this review, usage of NIV in elderly in specific conditions will be discussed.

\section{Acute Respiratory Failure in Elderly}

\section{De Novo Respiratory Failure}

Acute respiratory failure (ARF) is a devastating condition for patients that results from either impaired function of the respiratory muscle pump or from dysfunction of the lung. ARF is associated with a high hospital morbidity and mortality rate, ethical issues in managing end of life decisions and increased consumption of healthcare resources.

Acute hypoxaemic failure covers miscellanea of causes of lung damage including pneumonia, acute cardiogenic pulmonary oedema and also trauma in elderly.

The role of NIV in patients with hypoxaemic ARF is contraversial. The peculiar advantages of NIV versus IMV should be carefully weighed especially in elderly patients.

The benefit of NIV in patients with pneumonia is controversial due to high failure rates (11-14). NIV can be failed more frequently in subjects with de novo acute respiratory failure $(46 \%)$ than subjects with previous cardiac or respiratory disease (26\%). Worsening radiographic infiltrate $24 \mathrm{~h}$ after admission, maximum Sequential Organ Failure Assessment (SOFA) score and, after $1 \mathrm{~h}$ of NIV, higher heart rate and lower $\mathrm{PaO} 2 / \mathrm{FIO} 2$ and bicarbonate independently predicted NIV failure. Successful NIV was strongly associated with better survival. But if predictors for NIV failure are present, avoiding delayed intubation of patients with de novo acute respiratory failure may reduce mortality. In these patients respiratory muscle resting may improve respiratory mechanics (14).

The best hospital management of NIV in patients at an advanced age as in younger should require well-trained staff and a $24 \mathrm{~h}$ observation with an adequate monitoring of patients' condition severity during the NIV application in case a quick move to IMV is required especially in de novo respiratory failure.

\section{Acute Cardiogenic Pulmonary Edema/Acute Heart Failure}

NIV in addition to standard medical care is an effective and safe intervention for the treatment of elderly patients with acute cardiogenic pulmonary oedema (ACPE). 
The common clinical indications for NIV application in ACPE are dyspnea, hypoxemia and pulmonary congestion (15). The extravasation of fluid to alveoli that reduces gas exchange and produce hypoxia and also hypercapnia in severe cases. These symptoms are often caused in old patients mainly by afterload and fluid misdistribution rather than a total volume overload in the body (16). The goals of NIV use in the treatment of ACPE are to improve oxygenation, reduce the effort of breathing and increase cardiac output. Continious positive airway pressure (CPAP) achieves these goals by maintaining positive airway pressure throughout the respiratory cycle thereby preventing alveolar collapse at end-expiration.

CPAP increases lung compliance and decreases the effort of breathing, while decreasing cardiac preload and afterload. It improves arterial oxygenation ( $\mathrm{PaO} 2)$ by increasing the functional residual capacity of the lungs and reducing intrapulmonary shunt. When patients are treated using the CPAP, a high mean airway pressure is avoided and a lower mean intrathoracic pressure develops during inspiration, which has favorable effects in terms of the venous return and a reduced risk of barotrauma. Moreover, treatment with CPAP has beneficial effects on hemodynamics. Unlike CPAP, bilevel positive airway pressore (BiPAP) combines inspiratory positive air way pressure with positive end-expiratory pressure. As a result, the BiPAP differs from the CPAP due to providing inspiratory assistance that allows the muscles used in respiration to relax. Both the CPAP and BiPAP approaches are applied using either a nasal or an oronasal mask at the patient-ventilator interface.

Myopathy has been reported to be one of the most common clinical manifestations seen in patients with acute heart failure (HF). It results in muscle fiber atrophy, which leads to the substitution of type I muscle fibers with type II fibers. Consequent$l y$, there is a progressive reduction in the patient's capacity for exercise due to early fatigue and hyper- ventilation. Individuals with HF can develop both peripheral and respiratory muscle weakness (17).

The prevalence of inspiratory muscle weakness in outpatients with chronic HF has been reported to range between $30 \%$ and $50 \%$ (14). In older patients, the application of ventilatory support (i.e., CPAP or BiPAP) improves lung compliance, recruits previously collapsed alveoli, and reduces both the preload and afterload, which leads to an improvement in oxygenation and a reduction in the workload of the respiratory muscles (17-20). Moreover, it results in significantly reduced endotracheal intubation and mortality rates. Importantly, prior studies have indicated that an advanced age does not represent a limitation when it comes to the safe use of ventilatory support (18-21).

The complications associated with the use of NIV include air leaks, mask-related discomfort, skin breakdown, eye irritation, sinus congestion, oronasal drying, and patient-ventilator dyssynchrony (9). In addition, pneumothoraxes and pneumonias can occur following the administration of NIV, albeit less frequently than in the case of invasive ventilation. NIV may also result in endotracheal intubation being delayed, which can be associated with patient deterioration during the intervening period.

\section{Respiratory Failure due to Covid 19 Pneumonia}

Covid 19 pneumonia has seen frequently in elderly and mortality rates were higher than younger patients-NIV is an effective and common treatment for patients with mild to moderate acute respiratory failure. and (22) but it has some concerns in Covid 19 patients because coronavirus diffusion takes place by droplet transmission,(23)aerosolisation during NIV like intubation or bronchoscopy might represent a big danger, because of exposing other patients and health-care staff to an increased risk of infection. (24)Aerosolisation with nosocomial amplification of the infection can also potentially happen around the face mask during non-invasive 
ventilation (25).Accordingly, the efficacy and safety of non-invasive ventilation during viral pandemic infection are still debated. However, during pandemics, the number of intensive care unit beds for mechanical ventilation through tracheal intubation could rapidly become insufficient, (24)whereas non-invasive ventilation can be offered also outside the intensive care unit.

To increase staf and other patients safety during NIV, applying in negative pressure rooms, using a helmet mask as an interface can be considered to avoid aerosolisation. NIV should be aplied with ICU ventilators which allow the option of $\mathrm{FiO} 2$, permit visualisation of waveform display and allow seperate inspiratory and expiratory circuits. Filters should be attached to the ventilators' inspiratory and expiratory valve. ICU ventilators also recommended because of leak compansation. Accordingly, when facing a patient with acute respiratory failure of suspected Covid 19 the adoption of helmets masks should be prefered as possible. In clinical practice, pressure support ventilation with PEEP support is virtually the only mode. Emergency departments and intensive care units are increasingly applying NIV (22).

\section{Acute-on-Chronic Respiratory Failure}

Acute respiratory failure is often the final event in patients with chronic respiratory failure (26) especially those with chronic obstructive respiratory disease ( COPD). No consensus has yet been reached with regard to the best treatment and outcomes for elderly patients who have been admitted to the ICU following an episode of acute respiratory failure (27). However, NIV should be the first treatment chose for acute-on-chronic $(\mathrm{AOC})$ respiratory failure in appropriate patients.

It is important to note that neither ICU admission nor mechanical ventilation are necessarily associated with a poor prognosis in elderly patients who are experiencing acute exacerbations of COPD
(AECOPD). Individuals with chronic respiratory disorders represent a large proportion of those patients over 65 years of age who are admitted to an $\mathrm{ICU}$. Older patients with hypercapnia (i.e., $\mathrm{PaCO}_{2}>$ $45 \mathrm{mmHg}$ ) have been found to have a poor survival rate following an episode of acute hypercapnic respiratory failure (AHRF) (28). In these patients, the success of NIV is related to the number and the severity of their comorbidities.

The use of NIV to treat respiratory failure in old patients reduces the need for intubation, improves survival, and induces a faster resolution of respiratory distress compared with standard medical therapy ( SMT). In fact, rescue therapy involving NIV has been found to be very successful in the majority of cases (75\%) (27).

NIV not only improves the survival rate in older patients, but also reduces the major symptoms of respiratory distress, for example, tachypnea and dyspnea. It has previously been reported that the sensation of dyspnea and the respiratory rate are strongly correlated with the inspiratory load (29). Thus, it is likely that NIV could also prove useful in terms of relieving the sense of breathlessness in chronically ill elderly patients. The application of both inspiratory and expiratory support is important in acute and chronic settings in relation to reducing the inspiratory burden (27).

During an episode of $A O C$ respiratory failure in old patients, the use of NIV is associated with a reduced likelihood of meeting the endotracheal intubation (ETI) criteria, a higher survival rate, and the faster resolution of respiratory distress when compared with standard medical treatment. The use of NIV as a rescue therapy in those patients who met the intubation criteria represents the most likely explanation for the low mortality rate. This demonstrates the importance of NIV not only as a palliative measure but, also, as the primary treatment modality when intubation is either not wanted by the patient or not deemed necessary by the physician.

Interestingly, the high NIV success rate reported 
in patients with ARF due to AECOPD is also associated with a reduction in IMV-related complications (30).

In elderly patients with $A O C$ respiratory failure due to AECOPD, the initial NIV settings should involve an inspiratory positive airway pressure (IPAP or PS) of $10 \mathrm{cmH}_{2} \mathrm{O}$ and an expiratory positive airway pressure (EPAP or PEEP) of $4 \mathrm{cmH}_{2} \mathrm{O}$. The pressure should then be increased by $2-5 \mathrm{cmH} 2 \mathrm{O}$ every 10 minutes for as long as the patient's respiratory effort and arterial blood gas values warrant.

During the early stages of acute respiratory failure, the first application of NIV should last close to 24 hours. Then, on the basis of the patient's clinical and blood gas values, the application time should be reduced, although NIV should still be applied for at least five hours per day. In prior studies, the NIV implementation period has ranged from 4-15 days (31).

The use of NIV can allow patients to talk, eat, and partially clear secretions autonomously. Especially in the usage of appropiriate mask. Thus, NIV not only treats the cardiorespiratory problem, but also decreases the risk of delirium and malnutrition. (32). Furthermore, NIV reduces the need for sedatives, compared with IMV, which further contributes to prevent delirium and immobilization (33). The presence of delirium or dementia was not a barrier for the indication or for the administration of NIV; the presence of a pneumo-geriatric team allowed the symptoms to be controlled and the cooperation of the subjects to be obtained. In addition, NIV allows relatives to visit more frequently and for longer time.

\section{Pallative Care}

The use of NIV in palliative care settings is very important, especially in elderly patients, because it improves patients' dyspnea and so enhances their quality of life. Breathlessness is a cardinal symptom which progresses with advancing disease and has a profound impact on patients. The need for mechanical support is theoretically the main intervention when an organ is failing beyond a point in which any pharmacological intervention is ineffective or partially effective. The problem is understanding in the clinical practice as to when mechanical support may prove futile. The failure of weaning from IMV represents one of the major clinical problems in elderly patients, especially those with $\mathrm{AOC}$ respiratory failure and those who have several comorbidities.

The feasibility and the usefulness of NIV in relation to the palliative care of patients with acute respiratory failure who are nearing the end of their life have not yet been well demonstrated (34). NIV is often used for patients with terminal diseases to help alleviate their respiratory distress and provide some additional time, for example, to say goodbye to relatives and friends or to solve certain administrative issues, although most clinicians are unclear as to the goals of such care. It has been suggested that NIV may actually be inappropriate in this context due to the increased consumption of medical resources, the prolongation of the dying process, and the intensification of the patient's suffering (35).

\section{Domiciliary NIV in Eldery Patients}

The use of NIV is associated with a number of benefits in patients with respiratory conditions, including chronic respiratory diseases such as COPD, obesity hypoventilation syndrome, restrictive lung diseases, and a variety of neuromuscular conditions. However, it remains unclear whether these patients require domiciliary NIV, particularly if they are elderly. Although there is a paucity of data in this regard, it has been reported that the development of more comfortable interfaces, which are associated with more acceptable, safer, and better ventilators, has vastly expanded the patient population that could benefit from NIV (36). The application of domiciliary NIV can serve to reduce hospital and ICU admissions. It can also help to relieve chronic hypoventila- 
tion-related symptoms and so to maintain patients quality of life.

It has been reported that age, in and of itself, is not a barrier to the application of domiciliary NIV (37). NIV is known to be both effective and safe in elderly patients, many of whom have multiple comorbidities (e.g., significant cognitive impairment and acute delirium), at least in terms of acute presentations with respiratory insufficiency.

In conclusion, NIV is widely and successfully used in elderly patients with respiratory failure in an effort either to prevent endotracheal intubation and death (i.e., as supportive care) or to relieve the symptoms of patients' special conditions (i.e., as palliative care).

\section{Recommendations for NIV protocols:}

CPAP/PSV may be sufficient since hypoxemic respiratory failure is prominent. It should be applied between 8-15 $\mathrm{cmH}_{2} \mathrm{O}$. BIPAP can be applied to patients with hypercapnic or increased respiratory workload requiring ventilation support. The pres-

\section{REFERENCES}

1. Boumendil A, Somme D, Garrouste-Orgeas M, Guidet B. Should elderly patients be admitted to the intensive care unit? Intensive Care Med. 2007;33(7):1252. doi: 10.1007/s00134-007-0621-3. PMID: 17404703.

2. Higgins T; Teres D; Copes W S. ; et al. Assessing contemporary intensive care unit outcome: An updated Mortality Probability Admission Model (MPM0-III)*, Critical Care Medicine. 2007; 35 ( 3 ) : 827-835 doi: 10.1097/01.CCM.0000257337.63529.9F

3. Topeli A., Cakir B. Hospital survival of older patients admitted to a medical intensive care unit. Aging Clin Exp Res 2007.19, 69-74. https://doi.org/10.1007/ BF03325213

4. Ortaç Ersoy E, Topeli, A. Oxygen therapy systems in respiratory failure: Turkish journal of medical and surgical intensive care medicine. 2016: 7(3), 99-105. DOI:10.5152/dcbybd.2017.1329 sure support is adjusted to $8-16 \mathrm{cmH}_{2} \mathrm{O}$, PEEP 5-10 $\mathrm{cmH}_{2} \mathrm{O}$. It should be started with low values at the beginning and should be increased 1 or $2 \mathrm{cmH}_{2} \mathrm{O}$ at every 10-20 minutes. One and 2 hours from beginning respiratory workload (dyspnea, auxiliary respiratory muscles, respiratory pattern, respiratory rate and depth), state of consciousness and oxygenation should be evaluated.

If there is no response to NIV at the end of the 2nd hour, IMV with intubation should be considered.

NIV non-response / failure criteria: respiratory rate $>30 / \mathrm{min}$, tidal volume $>9 \mathrm{ml} / \mathrm{kg}$ ideal, minute ventilation $>12 \mathrm{~L} / \mathrm{min}$, use of auxiliary respiratory muscles, abdominal paradox, increase in respiratory distress, $\mathrm{SpO} 2<0.90, \mathrm{PaO} 2<60 \mathrm{mmHg}, \mathrm{PaO} 2$ / FiO2 <150, hypercapnia, $\mathrm{pH}<7.25$, mask intolerance, confusion, haemodynamic worsening, acute organ dysfunction (SOFA 2 increase)

NIV should not be administered in the presence of inability to protect the airway, coma, hemodynamic instability.

5. Yıldırım F, Öcal S, Ortaç Ersoy E, et al. High Flow Nasal Oxygen Therapy: From Physiology to Clinic Eurasian J Pulmonol 2017; 19: 54-64 DOI: 10.5152/ ejp.2017.38258

6. BG Katzung. Special Aspects of Geriatric Pharmacology, In: Bertram G. Katzung, Susan B. Masters, Anthony J. Trevor (Eds). Basic and Clinical Pharmacology. 10th edition, Lange, Mc Graw Hill, USA 2007, pp 983-90.

7. Wu Z, McGoogan JM. Characteristics of and Important Lessons From the Coronavirus Disease 2019 (COVID-19) Outbreak in China: Summary of a Report of 72314 Cases From the Chinese Center for Disease Control and Prevention. JAMA. 2020;323(13):12391242. doi:10.1001/jama.2020.2648

8. Segrelles Calvo G, Zamora Garcia E, Giron Moreno $\mathrm{R}$, et al. Non-invasive ventilation in an elderly population admitted to a respiratory monitoring unit: Causes, complications and one-year evolution. Arch Bronconeumol 2012;48:349-54 DOI: 10.1016/j. 


\section{arbr.2012.07.011}

9. Yıldırım F, Kara I, Ortaç Ersoy E. Noninvaziv mekanik ventilasyon sırasında sedasyon Tuberk Toraks 2016;64(3):230-239 ( article in Turkish) doi: 10.5578/ tt.10764

10. 1Schlitzer J, Haubaum S, Frohnhofen H. Treatment of chronic obstructive pulmonary disease in hospitalized geriatric patients. Z Gerontol Geriatr. 2014 Jun;47(4):288-92. doi: 10.1007/s00391-014-0645-6. PMID: 24803019

11. Esquinas A, Zamarro Garcia C. Non-invasive mechanical ventilation in elderly patients: moving towards a new strategy for hospital organization? Arch Bronconeumol. 2013; 49(6):275-6. doi: 10.1016/j.arbres.2012.11.007. PMID: 23332613.

12. Ferrer $M$, Esquinas $A$, Leon $M$,et al. Noninvasive ventilation in severe hypoxemic respiratory failure: a randomized clinical trial. Am J Respir Crit Care Med. 2003 Dec 15;168(12):1438-44. doi: 10.1164/ rccm.200301-0720C. Epub 2003 Sep 18. PMID: 14500259.

13. Agarwal R, Handa A, Aggarwal AN, et al. Outcomes of noninvasive ventilation in acute hypoxemic respiratory failure in a respiratory intensive care unit in north India. Respir Care. 2009 Dec;54(12):1679-87. PMID: 19961634.

14. Antonelli M, Conti G, Moro ML, et al. Predictors of failure of noninvasive positive pressure ventilation in patients with acute hypoxemic respiratory failure: a multi-center study. Intensive Care Med. 2001; 27(11):1718-28. doi: 10.1007/s00134-001-1114-4. Epub 2001 Oct 16. PMID: 11810114.

15. Vital FM, Ladeira MT, Atallah AN. Non-invasive positive pressure ventilation (CPAP or bilevel NPPV) for cardiogenic pulmonary oedema. Cochrane Database Syst Rev. 2013 1;(5):CD005351. doi: 10.1002/14651858.CD005351.pub3.

16. Gray A, Goodacre S, Newby DE, et al. Noninvasive ventilation in acute cardiogenic pulmonary edema. N Engl J Med. 2008; 10;359(2):142-51. doi: 10.1056/ NEJMoa0707992. PMID: 18614781.

17. Plaisance $P$, Pirracchio $R$, Berton $C$, et al. A randomized study of out-of-hospital continuous positive airway pressure for acute cardiogenic pulmonary oedema: physiological and clinical effects. Eur Heart J. 2007; 28(23):2895-901. doi: 10.1093/eurheartj/ ehm502. Epub 2007 Oct 29. PMID: 17967821.

18. Weng $\mathrm{CL}$, Zhao $\mathrm{YT}$, Liu $\mathrm{OH}$, et al. Meta-analysis:
Noninvasive ventilation in acute cardiogenic pulmonary edema. Ann Intern Med. 2010; 4;152(9):590-600. doi: 10.7326/0003-4819-152-9-201005040-00009.

19. Mariani J, Macchia A, Belziti C, et al. Noninvasive ventilation in acute cardiogenic pulmonary edema: a meta-analysis of randomized controlled trials. J Card Fail. 2011; 17(10):850-9. doi: 10.1016/j.cardfail.2011.05.010. Epub 2011 Jul 8. PMID: 21962424.

20. Vital FM, Ladeira MT, Atallah AN. Non-invasive positive pressure ventilation (CPAP or bilevel NPPV) for cardiogenic pulmonary oedema. Cochrane Database Syst Rev. 2013 31;(5):CD005351. doi: 10.1002/14651858.CD005351

21. Cabrini L, Landoni G, Oriani A, et al. Noninvasive ventilation and survival in acute care settings: a comprehensive systematic review and metaanalysis of randomized controlled trials. Crit Care Med. 2015; 43(4):880-8. doi: 10.1097/CCM.0000000000000819. PMID: 25565461.

22. Nava S, Hill N. Non-invasive ventilation in acute respiratory failure. Lancet. 2009;374(9685):250-9. doi: 10.1016/S0140-6736(09)60496-7. PMID: 19616722; PMCID: PMC7138083.

23. Wang C, Horby PW, Hayden FG, Gao GF. A novel coronavirus outbreak of global health concern. Lancet. 2020; 15;395(10223):470-473. doi: 10.1016/ S0140-6736(20)30185-9. PMID: 31986257; PMCID: PMC7135038.

24. Kain T, Fowler R. Preparing intensive care for the next pandemic influenza. Crit Care. 2019; 30;23(1):337. doi: 10.1186/s13054-019-2616-1. PMID: 31665057; PMCID: PMC6819413.

25. Hui DS, Chow BK, Ng SS, Chu LCY, Hall SD, Gin T, Sung JJY, Chan MTV. Exhaled air dispersion distances during noninvasive ventilation via different Respironics face masks. Chest. 2009;136(4):998-1005. doi: 10.1378/chest.09-0434. Epub 2009 May 1. PMID: 19411297; PMCID: PMC7094372.

26. Mehta S, Al-Hashim AH, Keenan SP. Noninvasive ventilation in patients with acute cardiogenic pulmonary edema. Respir Care. 2009; 54(2):186-95; discussion 195-7. PMID: 19173751.

27. Nava S, Grassi M, Fanfulla F, et al. Non-invasive ventilation in elderly patients with acute hypercapnic respiratory failure: a randomised controlled trial. Age Ageing. 2011 Jul;40(4):444-50. doi: 10.1093/ ageing/afr003. PMID: 21345841.

28. Cabrini L, Landoni G, Oriani A, et al. Noninvasive 
ventilation and survival in acute care settings: a comprehensive systematic review and metaanalysis of randomized controlled trials. Crit Care Med. 2015; 43(4):880-8. doi: 10.1097/CCM.0000000000000819. PMID: 25565461.

29. Wijkstra PJ, Lacasse Y, Guyatt GH, et al. A meta-analysis of nocturnal noninvasive positive pressure ventilation in patients with stable COPD. Chest. 2003; 124(1):337-43. doi: 10.1378/chest.124.1.337. PMID: 12853542 .

30. Hilbert G, Gruson D, Portel L, et al. Noninvasive pressure support ventilation in COPD patients with postextubation hypercapnic respiratory insufficiency. Eur Respir J. 1998; 11(6):1349-53. doi: 10.1183/09031936.98.11061349. PMID: 9657578.

31. Lynn J, Ely EW, Zhong Z, et al. Living and dying with chronic obstructive pulmonary disease. J Am Geriatr Soc. 2000; 48(S1):S91-100. doi: 10.1111/j.15325415.2000.tb03147.x. PMID: 10809462.

32. Plant PK, Owen JL, Elliott MW. One year period prevalence study of respiratory acidosis in acute exacerbations of COPD: implications for the provision of non-invasive ventilation and oxygen administration. Thorax. 2000; 55(7):550-4. doi: 10.1136/thorax.55.7.550. PMID: 10856313; PMCID: PMC1745812.
33. Brochard L, Isabey D, Piquet J, et al. Reversal of acute exacerbations of chronic obstructive lung disease by inspiratory assistance with a face mask. N Engl J Med. 1990 29;323(22):1523-30. doi: 10.1056/ NEJM199011293232204. PMID: 2122253.

34. Claessens MT, Lynn J, Zhong Z, et al. Dying with Lung Cancer or Chronic Obstructive Pulmonary Disease: Insights from SUPPORT. Journal of the American Geriatrics Society, 48: S146-S153. https://doi. org/10.1111/j.1532-5415.2000.tb03124.x

35. 35-Scala R, Nava S. NIV and palliative care. In European Respiratory Monograph, 2008, 41, 287-306. Copyright ERS Journals Ltd 2008; ISSN 1025-448xEur Respir Mon. 2008;41:287-306.

36. Simonds AK. Home ventilation. Eur Respir J Suppl. 2003;47:38s-46s. doi:10.1183/09031936.03.00029803. PMID: 14621116.

37. De Backer L, Vos W, Dieriks B, et al. The effects of long-term noninvasive ventilation in hypercapnic COPD patients: a randomized controlled pilot study. Int J Chron Obstruct Pulmon Dis. 2011;6:615-24. doi: 10.2147/COPD.S22823. PMID: 22135493; PMCID: PMC3224655. 